\title{
Design como experiência ${ }^{1}$
}

\section{Design as experience}

Michele Marconsini, Pontifícia Universidade Católica do Rio de Janeiro. michelemarconsini@gmail.com

Luiza Novaes, Pontifícia Universidade Católica do Rio de Janeiro.

lnovaes@puc-rio.br

\section{Resumo}

No presente artigo, trazemos a concepção de experiência formulada por Jorge Larrosa para o contexto de ensino-aprendizagem no campo do Design, com ênfase na experiência do designer em processos projetuais. Ao articularmos essa concepção de experiência com conceitos de projeto delineados por Miller, Argan e Findeli, ressaltamos as dimensões idiossincráticas e subjetivas que permeiam o processo projetual e que afetam o modo como designers lidam com os limites de suas ideias e com a imprevisibilidade de suas criações. Nessa perspectiva, refletimos sobre as possibilidades de formação de designers enquanto sujeitos da experiência encontrando caminhos para tal em processos de ensino-aprendizagem por meio de projetos que valorizem a reflexão que ocorre no encontro com a diferença, abordagem que denominamos Design Reflexivo.

Palavras-chave: Experiência, Projeto de Design, Design Reflexivo

\begin{abstract}
In this article, we bring the conception of experience formulated by Jorge Larrosa into the context of teaching and learning in the field of Design, with an emphasis on the experience of the designer in design processes. When articulating this conception of experience with design concepts outlined by Miller, Argan and Findeli, we highlight the idiosyncratic and subjective dimensions that permeate the design process and that affect the way designers deal with the limits of their ideas and the unpredictability of their creations. In this perspective, we reflect on the possibilities of training designers as subjects of experience, finding ways to do so in teaching-learning processes through projects that value the reflection that occurs in the encounter with difference, an approach that we call Reflective Design.
\end{abstract}

Keywords: Experience, Design Project, Reflective Design

\footnotetext{
${ }^{1}$ O presente trabalho foi realizado com apoio da Coordenação de Aperfeiçoamento de Pessoal de Nível Superior - Brasil (CAPES) - Código de Financiamento 001
} 


\section{Introdução}

No campo do Design, o termo experiência geralmente é associado a uma linha de pensamento focada na experiência do usuário, em suas atitudes e comportamentos, e na interação sujeito/objeto. A partir da crítica elaborada por Heinrich (2018) acerca da compreensão e do uso que se faz do termo experiência, levantamos algumas questões sobre as possibilidades de experiência no campo, sublinhando a interação sujeito/sujeito (designer/usuário).

Tendo como fio condutor o conceito de experiência formulado pelo filósofo contemporâneo e educador Jorge Larrosa, trazemos essas reflexões para o contexto de ensino-aprendizagem no campo do Design, com ênfase na experiência do designer em processos projetuais. Ao articularmos essa concepção de experiência com os conceitos de projeto delineados por Miller, Argan e Findeli ressaltamos as dimensões idiossincráticas e subjetivas que permeiam o processo projetual e que afetam o modo como designers lidam com os limites de suas ideias e com a imprevisibilidade de suas criações.

Nessa perspectiva, consideramos possibilidades de formação de designers enquanto sujeitos da experiência, encontrando caminhos para tal em processos de ensino-aprendizagem por meio de projetos que valorizem a reflexão que ocorre no encontro com a diferença, abordagem que denominamos Design Reflexivo.

\section{Sobre o conceito de experiência no campo do Design}

Fabiana Heinrich (2018), em sua tese Crítica da experiência como mercadoria no campo do Design, critica a compreensão e o uso que se faz do termo experiência no campo do Design como algo natural, de sentido fixo, não cambiante e como mercadoria passível de ser projetada. Após examinar definições de experiências no campo do Design, Heinrich argumenta que o que se oferece no campo são promessas - que podem ou não se realizar - de que o uso de um objeto ou mercadoria se dará de determinado modo e de que a experiência consequente desse uso será da maneira prevista. Portanto, a experiência poderá ser uma decorrência, mas não pode ser projetada em si.

Dessa forma, a autora alerta para o fato de que o entendimento de se projetar a/para a experiência na verdade se traduz em projetar um usuário, geralmente anônimo, apolítico, inexistente (e não em projetar para o usuário). Consequentemente, esse usuário é compreendido como um ser passivo, que não resiste, que não se manifesta e, portanto, sem espaço para o contraditório. A autora questiona: como projetar algo ou projetar para algo descrito como abstrato, emocional, genuíno, individual, não copiável, tendo em vista que um projeto resulta em algo concreto, racional, copiável, coletivo? Heinrich afirma, ainda, que se os projetos são desenvolvidos com o intuito de gerar lucro, ao considerar a experiência comercializável, 
entende-se esta como mercadoria. Considerando esses questionamentos, qual seria a possibilidade de uma experiência no campo do Design?

Heinrich (2018) investiga a pluralidade de significados do termo experiência, apontando a sua complexidade, e faz uma reflexão acerca de que tais significados podem ser atualizados para uma variedade de propósitos diferentes e antagônicos, permitindo tanto a lamentação de que a experiência já não é possível, quanto a noção de que vivemos em uma "sociedade da experiência". As diferentes noções serviriam "politicamente como guias normativos para práticas sancionadas pelas instituições sociais e culturais" (HEINRICH, 2018, p.87).

Larrosa (2011), na posição de filósofo contemporâneo e educador, a partir de sua definição de experiência lamenta a escassez de experiências no campo da educação. $\mathrm{O}$ autor critica as tentativas na pedagogia de sempre controlar a experiência, submetê-la a uma causalidade técnica e conduzi-la para um fim preestabelecido. Segundo Larrosa, ao prevenir o que ela tem de incerto, os educadores impossibilitam o que ela poderia ter de pluralidade e a convertem em um caminho seguro para um modelo prescritivo de formação.

$\mathrm{O}$ autor reivindica, então, sua concepção de experiência nos espaços educacionais como espaços em que também podem (ou deveriam) ocorrer imprevistos. "Espaços em que às vezes vacilam nossas palavras, nossos saberes, nossas técnicas, nossos poderes, nossas ideias, nossas intenções. Como na vida mesma." (LARROSA, 2011,24-25). Espaços em que podemos (ou deveríamos) habitar também como sujeitos da experiência e não apenas como especialistas.

A experiência para Larrosa (2011) supõe um acontecimento (grifo do autor), um passar de algo que não sou eu. Esse "algo que não sou eu" significa algo que não é uma projeção de mim, nem de minhas ideias, nem de meus projetos, nem de meus sentimentos, nem de minhas intenções. Algo que não depende do meu saber, do meu poder, de minha vontade. Significa "outra coisa que eu". É outra coisa do que aquilo que eu penso, do que eu antecipo, do que eu posso, do que eu quero. A essa "outra coisa que eu" o autor define o princípio da exterioridade, ou da alteridade, como um dos princípios que constitui a experiência. Nesse sentido, não há experiência sem a aparição de alguém, ou de algo, ou de um acontecimento, que é exterior a mim, estrangeiro a mim.

Ao analisar o significado da palavra experiência, Larrosa (2002) discorre sobre o que define ser uma experiência. De sua origem do latim experiri, que significa provar (experimentar), o autor a define como um encontro ou uma relação com algo que se experimenta, que se prova. Do radical periri, que se encontra também em periculum, perigo, e da raiz indo-européia per, bem como dos derivados dessa raiz em grego (peirô, atravessar; pera, mais além; perâ̂, passar através, perainô, ir até o fim; peras, limite), o autor a relaciona com a ideia de travessia, de percurso, de passagem.

O sujeito da experiência tem algo desse ser fascinante que se expõe atravessando um espaço indeterminado e perigoso, pondo-se nele à prova e buscando nele sua oportunidade, sua ocasião. A palavra experiência tem o ex de exterior, de estrangeiro ${ }^{2}$, de exílio, de estranho $^{3}$ e também o ex de existência. A experiência é a passagem da existência, a passagem de um ser que não tem essência ou razão ou fundamento, mas que simplesmente

\footnotetext{
${ }^{2}$ Em espanhol, escreve-se extranjero. (Nota do tradutor)

${ }^{3}$ Em espanhol, extraño. (Nota do tradutor)
} 
"ex-iste" de uma forma sempre singular, finita, imanente, contingente. Em alemão, experiência é Erfahrung, que contém o fahren de viajar. (LARROSA, 2002, p.25)

No entanto, seguindo a definição do autor, esse acontecimento, um passar de algo que não sou eu, passa em mim. O lugar da experiência sou eu. É em mim, em minhas ideias, em minhas representações, em meus sentimentos, em meus projetos, em meu saber, em minha vontade, onde a experiência tem lugar. O lugar da subjetividade. A experiência é sempre subjetiva.

Então a experiência tem um movimento ao encontro de algo que não sou eu e um movimento de volta, no qual esse encontro me afeta, produz efeitos em mim, no que eu sou, no que eu penso, no que eu sinto, no que eu sei, no que eu quero. Nesse movimento, o autor define o princípio da reflexividade. Por ser reflexiva, a experiência tem uma dimensão transformadora, que me faz outro do que sou. Porque se trata de um sujeito capaz de ser afetado, capaz de que algo lhe aconteça e o transforme.

Trata-se, portanto, de um sujeito sensível, exposto, aberto a sua própria transformação. Por conseguinte, um sujeito incapaz de experiência seria um sujeito autodeterminado, definido por seu saber, por sua vontade, inatingível e apático, ou seja, incapaz de ser transformado. Daí a relação constitutiva apresentada pelo autor entre a ideia de experiência e a ideia de formação (diferente da ideia de aprendizagem no sentido cognitivo ou da educação como algo que tem a ver com o saber). Dessa forma, o resultado da experiência é a formação ou a transformação do sujeito. O sujeito da experiência é como uma superfície de sensibilidade em que algo passa e deixa um vestígio, uma marca, um rastro, uma ferida.

Ao lamentar a escassez de experiências na sociedade contemporânea, Larrosa (2011) critica a relação que temos com o conhecimento enquanto mercadoria.

Temos o conhecimento, mas como algo exterior a nós, como algo útil ou uma mercadoria. [...] Consumimos arte, mas a arte que consumimos nos atravessa sem deixar nenhuma marca em nós. Estamos informados, mas nada nos comove no íntimo. [...] Sabemos muitas coisas, mas nós mesmos não mudamos com o que sabemos. (LARROSA, 2011, p.13)

Para Larrosa (2011), a experiência como formação supõe o cancelamento dessa fronteira entre o que sabemos e o que somos, entre o que passa (e o que podemos conhecer) e o que nos passa (como algo a que devemos atribuir um sentido em relação a nós mesmos). O saber da experiência não está, como o conhecimento científico, fora de nós, e só tem sentido no modo como configura uma personalidade, um caráter, uma sensibilidade.

Diante do que foi exposto, trazemos essas reflexões para o contexto educacional no campo do Design, no que se refere ao processo de ensino-aprendizagem por meio de projetos, já que o autor nos instiga a pensar sobre a possibilidade de experiências na educação. De que forma, então, podemos habitar como sujeitos da experiência no campo do Design? Em que momentos, no processo de ensino-aprendizagem, vacilam nossos saberes, nossas técnicas, nossas ideias, nossas intenções? E como esses momentos nos afetam?

Para seguirmos com a reflexão, faz-se necessário discorrermos sobre o conceito de projeto no campo do Design. 


\section{Sobre o conceito de projeto no campo do Design}

Segundo Miller (1988), a palavra design em inglês é utilizada tanto como verbo quanto substantivo. Ao definir design, o autor ressalta o entendimento da palavra como verbo, acentuando que esta deve ser compreendida enquanto processo. Para Miller, design é um processo não linear (grifo nosso) de pensamento que envolve várias ações para a criação de algo que está sendo projetado. Portanto, a coisa criada não é design, mas o seu resultado.

Argan (1993), em A história na metodologia do projeto, define projeto como proposta de mudança de algo, o que supõe uma análise crítica do existente e, por isso, pode-se dizer que pressupõe uma ideia de valor. Nesse sentido, afirma que o projeto é um procedimento de valorização. Um processo, uma sucessão de ações de valorização. $\mathrm{O}$ autor define o que seria valor nesse contexto.

O valor não é algo que está ligado às coisas, mas uma atribuição de significação que se dá às coisas. Se não compreendo nada de pintura, se sou completamente alheio à pintura e se me mostram um quadro de Rafael ou um quadro de Cézanne, isso não terá nenhum valor para mim. Isso só assume um valor no momento em que eu o reconheço, no momento em que seja eu quem lhe atribui um valor (ARGAN, 1993, p.4).

Para o autor, esse processo de valorização é um problema já que o projeto deixa traços (objetos), e o objeto é qualquer coisa que é definida por e, ao mesmo tempo, define o sujeito.

Mas o que é o sujeito? O sujeito é aquele pelo qual uma coisa é um objeto. Um objeto é uma coisa que é refletida, feita, organizada por um sujeito. E ao mesmo tempo em que define a individualidade do objeto, o objeto definiu minha individualidade. Eu sou um indivíduo enquanto sujeito, sujeito enquanto penso um objeto. (ARGAN, 1993, p.4)

Argan (1993) opõe à ideia de projeto a ideia de programa, por não ser o resultado de uma crítica. $\mathrm{O}$ autor salienta que um esquema de desenvolvimento quase automático de uma tecnologia não se configura como projeto e sim como programa, pois nesse caso trata-se de uma projeção de si. Assim, Argan (1993) reflete sobre os problemas de um automatismo, com as possibilidades tecnológicas de criar mecanismos capazes de se corrigir e questiona o consumo fugaz das imagens produzidas pelo aparato tecnológico, tornando a imaginação uma atividade somente de recepção. A imaginação que seria, nas palavras do autor, pensar a posteridade, por meio da qual estaríamos pressupondo uma ideia de valor. No entanto, o autor distingue o projetar de uma atividade científica "pois sabemos muito bem que as coisas se darão de uma maneira totalmente diferente do modo como as projetamos" (ARGAN, 1993, p.02).

Heinrich (2018) destaca a importância de percebermos e reconhecermos os limites dos nossos projetos, o que estamos projetando e o que fica de fora. De acordo com a autora, criar objetos significa que criamos coisas para serem usadas. "As pessoas são partes ativas do sistema e por que são muito menos previsíveis e menos compreendidas do que os computadores e outras partes tecnológicas do sistema, elas exigem um estudo e compreensão ainda maiores" (HEINRICH, 2018, p.31). 
Ao refletir sobre uma abordagem sistêmica do processo projetual, Findeli (2000) delineia uma estrutura lógica desse processo, na qual a produção de um artefato não é o único resultado do projeto, e destaca a possibilidade de transformação do designer e do usuário.

A produção de um objeto material não é o único modo de transformar um estado $\mathrm{A}$ em um estado B; como designer e usuário estão envolvidos em um processo, acabam se transformando também, e esta dimensão de aprendizagem deveria ser considerada também como parte do projeto ${ }^{4}$. (FINDELI, 2001, p.10 - tradução nossa).

Nessa concepção de projeto, o designer não atua sobre, mas dentro do sistema. A tarefa do designer é compreender sua dinâmica sendo o estado B um estado transitório, mais ou menos estável, entre várias possibilidades, aquela definida pelo designer e pelo usuário de acordo com seus conjuntos de valores.

Tecendo uma articulação entre as noções de projeto de Miller (1988), de Argan (1993) e de Findeli (2001), podemos considerar que o projeto é um processo não linear de pensamentos e ações de valorização, no qual designers e usuários são afetados. Nessa concepção, os aspectos subjetivos que permeiam o processo projetual são ressaltados.

Observamos uma abordagem de ensino-aprendizagem desenvolvida em um curso de graduação em Design, que considera as dimensões idiossincráticas e subjetivas que permeiam o processo projetual. Tal abordagem decorreu de uma mudança de filosofia de ensino que valoriza a cultura local e proporciona aos estudantes a oportunidade de vivenciar um processo que leva em consideração a imprevisibilidade dos usos dos objetos criados. Percebemos que essa abordagem de ensino-aprendizagem traz a possibilidade de entendimento de que $\mathrm{o}$ desenvolvimento de um projeto é uma construção dinâmica e não linear na qual as diversas possibilidades de sentido/usos dos objetos criados (ações de valorização) fornecem informações a serem consideradas pelos estudantes e que, por vezes, essas informações podem contradizer suas ideias e intenções iniciais.

Essa filosofia de ensino é consequência de uma insatisfação com práticas de projeto realizadas em sala de aula em torno da relação professor/aluno ${ }^{5}$, em que os usuários eram fictícios. Os professores propuseram, então, que durante o desenvolvimento dos projetos os estudantes tivessem o envolvimento direto com o usuário para quem se projeta, tornando-o um parceiro em todo o processo. Os projetos passaram a ser desenvolvidos em organizações ou grupos externos à universidade, mediados por interlocutores que são identificados nesses grupos. O interlocutor é um usuário em potencial com uma motivação intrínseca, envolvido em uma ação ou série de ações já em vigor, com quem os designers interagem durante todo o processo (TOLEDO; PACHECO, 2014). Assim, o processo projetual que antes se restringia à relação professor/aluno tornou-se parte de uma situação concreta em que há usuários/parceiros ativos (PACHECO, 1996).

(...) por experiência própria no mercado de trabalho, sabíamos que este meio físico-social fora da universidade era muito rico e estava em constante transformação, proporcionando

\footnotetext{
${ }^{4}$ The production of a material object is not the only way to transform state A into state B; and since the designer and the user also are involved in the process, they end up being transformed, too, and this learning dimension should be considered as pertaining to the project.

${ }^{5} \mathrm{O}$ termo aluno é adotado para se referir a processos de ensino-aprendizagem restritos ao ambiente sala de aula e à relação com o professor.
} 
assim um trabalho interessante, na medida em que ele sempre opõe resistência às ideias das pessoas que estão trabalhando com ele. A resistência é forte e por isso propicia um bom exercício. (RIPPER, 1995 apud PACHECO, 1996, p.9).

A presença do parceiro no processo projetual traz outros elementos de aprendizagem que transcendem os aspectos técnicos e objetivos. Ao lidar com um usuário ativo, que resiste e que se manifesta, o exercício ganha espaço para o contraditório. A tentativa de projetar para o usuário - e não de projetar um usuário - possibilita um exercício na formação de designers para a compreensão das influências contextuais de sua atuação. As frustrações que podem ocorrer nesse processo trazem um entendimento dos limites no campo que os designers irão atuar.

Assim, as experiências pelas quais passam os estudantes nessa abordagem de ensinoaprendizagem referem-se também, seguindo Larrosa (2011), com o não saber, com o limite do que sabemos, com o limite das nossas ideias, da nossa linguagem, com o limite do que podemos. Parafraseando Larrosa (2011), o importante (como dimensão de aprendizagem, de transformação) não é o resultado de um projeto, mas o modo como em relação às possibilidades de sentido/uso observadas posso formar ou transformar minhas ideias, meus pensamentos, meus sentimentos, minha linguagem. Trata-se de uma relação de escuta e não de apropriação. Na escuta alguém está disposto a ouvir o que não sabe, o que não quer, o que não precisa. Está disposto a transformar-se em uma direção desconhecida.

Dessa forma, podemos nos perguntar onde se encontra a dimensão de exterioridade, de alteridade e de transformação no designer? Onde é possível a capacidade de escuta do que não sabe, do que não quer? A possibilidade de transformação do designer dependerá do quanto este estará "disposto a perder o pé e a deixar-se tombar e arrastar pelo que lhe vem ao encontro" (LARROSA, 2011, p.13). Trata-se de pensar o design como algo que nos forma (ou nos deforma ou nos trans-forma), como algo que nos constitui ou nos põe em questão naquilo que somos. Argan (1993) salienta a possibilidade de mudanças na atividade projetual como distinção do automatismo programático por serem imprevisíveis e subjetivas, por serem resultados de uma crítica do existente.

O projeto pode ser mudado como cada um de nós pode mudar seu comportamento segundo as circunstâncias do real. Mas o programa, ao contrário, não aceita ser mudado, porque o programa é uma espécie de automatismo que é alheio à vontade humana, e se diz que é o produto de uma tecnologia moderna. É o computador que programa (ARGAN, 1993, p.06).

Para nós, designers, estende-se o questionamento. Quando projetamos estamos atuando com automatismo? Qual o rastro que fica após as experiências pelas quais passamos ao projetar? A fim de ampliar essa reflexão citamos um texto, no qual Larrosa (2011) provoca o sujeito leitor, trocando-o pelo sujeito designer.

Um designer que, após projetar, se olha no espelho e não nota nada, não lhe passa nada, é um designer que não fez nenhuma experiência. Compreendeu o processo. Domina todas as estratégias de linguagem e comunicação que os designers têm que dominar. Seguramente é capaz de responder bem a todas as perguntas que lhe façam sobre design. (...) é um designer que não põe em jogo a si mesmo no que projeta, um designer que pratica um modo de projetar no qual não existe relação entre o processo e sua própria subjetividade. É também um designer que vai ao encontro do usuário, mas que são caminhos só de ida, caminhos sem reflexão, é um designer que não se deixa dizer nada. Por último, é um designer que não se transforma. Em seu processo não há reflexividade, nem transformação. Ainda que compreenda perfeitamente o que projeta. Ou, talvez, precisamente porque 
compreende perfeitamente o que projeta. Porque é incapaz de uma experiência. (LARROSA, 2011, p.9).

\section{O sujeito da experiência no Design Reflexivo}

De que forma, então, podemos habitar como sujeitos da experiência no campo do Design? Em que momentos vacilam nossos saberes, nossas técnicas, nossas ideias, nossas intenções? E como esses momentos nos afetam? Onde se encontra a dimensão de exterioridade, de alteridade e de transformação no design(er)?

$\mathrm{Na}$ abordagem de ensino-aprendizagem observada e relatada anteriormente, o estudante designer está sujeito a lidar com as condições de possibilidades em um contexto a ser definido pela atuação dos participantes (ações de valorização), uma realidade não controlada pelo estudante e pelo professor. No entanto, lidar com uma situação incerta, na qual há outras perspectivas a serem consideradas, requer uma mudança de postura em relação ao conhecimento, como nos instiga Larrosa (2011).

No processo de design, as ações (de valorização) associadas à atividade de pensamento (in)formam visões de mundo. $\mathrm{O}$ designer, ao projetar, transporta uma "imagem de possibilidade" que se constitui na sua visão de mundo, definindo sua proposta de mudança de algo. Contudo, a concretização dessa proposta depende das ações (de valorização) dos usuários. Tais ações fornecem informações importantes a serem consideradas pelos designers em seus processos projetuais para o entendimento do contexto de atuação a partir de uma atitude relacional. A atitude relacional reside no trabalhar com (grifo nosso). Mas é importante destacar que esse com implica lidar com a diferença e não se restringe a um consenso resultante de um trabalho coletivo. Propomos avançar essa reflexão para uma relação dialógica intersubjetiva que possibilite o encontro da diferença, da heterogeneidade, da pluralidade.

Biesta (2013), discorre sobre a ideia de espaço intersubjetivo, ressaltando a dimensão social do espaço em que o sujeito emerge como um ser singular e único. $\mathrm{O}$ autor parte de reflexões nas quais recorre aos pensamentos de Foucault sobre a morte do sujeito, de Levinas sobre a concepção de alteridade e de Arendt sobre a ideia de ação. Nessa discussão, as singularidades dos sujeitos são possíveis na relação dos sujeitos com outros, no encontro com a diferença. Agir nesse sentido corresponde à condição humana da pluralidade, pois reside no fato de que sempre agimos sobre seres que são capazes de suas próprias ações.

Assim, não se trata de um processo cosubjetivo, no qual os indivíduos trabalham juntos e produzam coisas. "O agente que é revelado no ato não é um autor ou um produtor, mas um sujeito no duplo sentido da palavra, a saber, alguém que iniciou a ação e alguém que sofre as consequências" (BIESTA, 2013, p.47).

A compreensão da ação proposta por Arendt revela que o que torna nosso ser com outros difícil é, ao mesmo tempo, o que torna nosso ser com outros possível - isto é, desde que concebamos nosso ser com outros como ser com outros. Afinal, há sempre a opção de impor nossos inícios aos outros, com isso negando e erradicando a outridade do outro. Esse 
é o ponto em que a ação se torna fazer, isto é, em que o modo de atividade se torna tecnológico. (BIESTA, 2013, p.75)

Em muitas situações (conscientes disso ou não), há uma imposição nas ações dos designers que acabam por eliminar a outridade do outro. Lima (2016), por exemplo, ressalta as relações de poder envolvidas nas ações dos designers no âmbito profissional ao retratar as relações entre designers e artesãos.

Muitas vezes o designer não quer dividir o poder e projetar juntamente com o artesão e acaba impondo um projeto sem futuro. Uma situação curiosa, porque o designer, ao menos, deveria ser capacitado para trabalhar em equipes multidisciplinares. Forty (2007) destaca que essa é uma atividade por natureza, social e não puramente individual. Entretanto, se disseminou um mito da autonomia criativa, da onipotência sobre todo seu processo de produção e falsa ideia de um gênio criativo. Isso gera nos designers ilusões grandiosas sobre a natureza de seu trabalho, tornando alguns profissionais prepotentes, que não estão preparados para compartilhar o poder. (LIMA, 2016, p.17)

A autora analisa as influências do mercado na produção de subjetividades e como essas influências se manifestam nas ações de designers, contribuindo para uma prática reducionista que não considera as particularidades da comunidade artesã, ou seja, uma prática na qual os designers eliminam a outridade dos artesãos.

A educação tem um importante papel na formação de designers capazes de refletir sobre as consequências de suas próprias atuações e de lidar com a pluralidade. Para isso, é necessário ampliar práticas educacionais que os capacite a lidar com situações que escapam ao seu controle, situações em que possam lidar com aspectos conflitantes e ambíguos de suas criações.

É o movimento de reflexividade que torna possível a transformação do design(er). Um movimento ao encontro do usuário, mas que não é um movimento só de ida, pois não se trata de uma projeção de si, mas de lidar com as possibilidades de mudanças e de transformação dos próprios pensamentos e ideias. É uma atividade de escuta, de exposição do sujeito em oposição a uma reação automática às informações ou à imposição de ideias.

A abordagem de um Design Reflexivo em processos de ensino-aprendizagem por meio de projetos oferece aos estudantes espaços nos quais possam lidar com elementos surpresas, imprevisíveis e singulares, espaços que possibilitam um processo de escuta na reflexão sobre os usos inesperados dos objetos projetados, sobre as ações dos usuários e sobre suas próprias ações. Espaços que lhes permitam lidar com a imprevisibilidade e a reformulação de suas ideias, ou seja, espaços nos quais possam habitar como sujeitos da experiência.

\section{Considerações}

Vale a pena salientar que quando tratamos de aspectos técnicos no campo do Design, a objetividade do conhecimento científico é indispensável. No entanto, por se tratar de uma atividade de criação, de transformação, na qual lidamos com pessoas e criamos para e com pessoas, deve(ria) servir também como espaços para habitarmos como sujeitos da experiência, espaços em que possamos lidar com a imprevisibilidade, em que possamos colocar o especialista de lado e nos permitir momentos de escuta. 
Assim, ressaltamos a imprevisibilidade, a (inter)subjetividade e a reflexividade como características indispensáveis para a (trans)formação de designers em processos de ensinoaprendizagem por meio de projetos no campo do Design.

\section{Referências}

ARGAN, G. C. A História na Metodologia do Projeto. Revista Caramelo, São Paulo, no 6 , p; 156-170, 1993.

BIESTA, G. Para além da aprendizagem - Educação democrática para um futuro humano. Coleção: Educação: Experiência e Sentido. Tradução: Rosaura Eichenberg. Rio de Janeiro: Autêntica, 2013.

FINDELI, A. Rethinking Design Education for the 21st Century: theoretical, methodological and ethical discussion. Design Issues: Vol. 17, No. 1, p.5-17 2000.

HEINRICH, F. O. Crítica da experiência como mercadoria no campo do Design. Rio de Janeiro, 2018. Tese de Doutorado. Acesso em: nov. 2018

LARROSA, J. Notas sobre a experiência e o saber de experiência. Revista Brasileira de Educação. Rio de Janeiro, n.19, Jan./Abr. 2002, p.20-28.

Experiência e Alteridade em Educação. Revista Reflexão e Ação. Santa Cruz do Sul, v.19, n2, p.04-27, jul./dez. 2011

LIMA, M. F.; DESIGN E ARTESANATO: relações de poder, p. 11-20 . In: Anais do 50 Simpósio Brasileiro de Design Sustentável [=Blucher Design Proceedings, v.2, n.5]. São Paulo: Blucher, 2016.

MILLER, W. R. Definition of Design. In: wrmDesign.com. 2004. Acesso em: 16 nov. 2015.

PACHECO, H. S. O Design e o Aprendizado. Barraca: quando o Design Social deságua no Desenho Coletivo, 1996. Dissertação de Mestrado. Acesso em: 19 nov. 2015.

PACHECO, H. S. TOLEDO, G. The Word Game: a Social Design research tool to visually communicate values, beliefs, and intrinsic motivation. In: Coutinho, Solange G.; Moura, Monica; Campello, Silvio Barreto; Cadena, Renata A.; Almeida, Swanne (orgs.). Proceedings of the 6th Information Design International Conference, 5th InfoDesign, 6th CONGIC [= Blucher Design Proceedings, num.2, vol.1]. São Paulo: Blucher, 2014.

\section{Sobre as autoras}

\section{Michele Marconsini}

Doutoranda (desde 2018) e Mestre em Design (2017) pela Pontifícia Universidade Católica do Rio de Janeiro. Graduou-se em Desenho Industrial - Programação Visual pela Universidade Federal do Espírito Santo (2008) e especializou-se em MBA em Marketing pela Fundação Getúlio Vargas (2014). Participa do grupo de pesquisa "Experiências e ambientes interativos" realizada na Pontifícia Universidade Católica do Rio de Janeiro. michelemarconsini@gmail.com

\section{Luiza Novaes}

Doutora em Design pela PUC-Rio, Brasil e Mestre em Fotografia e Media pela School of Visual Arts, New York, USA. Designer, pesquisadora investiga o design como experiência e mediação; interatividade e comunicação visual. Atua como professora na Graduação e na Pós-graduação 
ESTUDOS EM DESIGN
DESIGN ARTICLES

em Design da PUC-Rio. É líder de dois grupos inscritos no Diretório de Grupos de Pesquisa do CNPq: "Experiências e Ambientes Interativos" e "Interfaces Físicas Experimentais".

lnovaes@puc-rio.br 